\title{
COLOMBIA Y VENEZUELA. MODELOS EMERGENTES EN LA NUEVA POLÍTICA LATINOAMERICANA.
}

Carlos Moreira

\begin{abstract}
Resumen
Este trabajo aborda el estudio de los modelos de políticas públicas latinoamericanas pos Consenso de Washington, fundamentalmente los que hemos denominado Modelos Bogotá y Caracas. Los mismos se construyen a la manera de los tipos ideales weberianos, esto es, acentuando las características de los casos históricos que le sirven de referencia (Colombia y Venezuela en la primera década del siglo XXI, respectivamente). Aunque vale aclarar que de ninguna manera será posible reconocer completamente estos fenómenos históricos en la definición del modelo o tipo ideal. Los elementos o variables que se toman en cuenta para la comparación son la institucionalidad democrática, la justicia social, las relaciones entre Estado y mercado y la integración al mundo. La consideración de estos elementos permiten ubicar los diferentes casos nacionales (Uruguay, Brasil, Argentina, Chile, Ecuador y Bolivia) en relación a los modelos enunciados.
\end{abstract}

Palabras Claves: Política Latinoamericana; Estudios Comparados; Gobierno Colombia; Gobierno Venezuela.

\begin{abstract}
This article examines the Latin American public policy programs postWashington Consensus, named as the Caracas and Bogotá models. These models are constructed in an Weberian ideal sense, that is, placing special attention to the historical characteristics of the historical cases that serve as reference (Colombia and Venezuela in the first decade of the XXI century). Although it should be mentioned that it is not possible to recognize all these historical phenomena in the ideal model definition. The elements or variables that are taken into account for comparison are: democratic institutionalization, social justice, the relationships between State and market and the integration to the world. Bringing these elements into consideration, makes possible to place the different national cases (Uruguay, Brazil, Argentina, Chile, Ecuador and Bolivia) in relation to the models proposed.
\end{abstract}

Key-Words: Latin America politics; comparative studies; Colombia Government; Venezuela Government.

\section{Introducción}

Durante la etapa neoliberal de los años ochenta y noventa del siglo pasado los gobiernos latinoamericanos impulsaron una serie reformas estructurales que tuvieron tres consecuencias (negativas) para la región y que en algún momento parecieron transformarse en 
obstáculos insuperables.

En primer lugar, el avasallamiento de la institucionalidad democrática hasta dejarla reducida a los aspectos electorales de la sucesión de los gobernantes llevaron a explosiones de demandas sociales y problemas graves para la gobernabilidad de la región. En segundo lugar, el ataque al sistema de bienestar desarrollista iniciado en los años setenta llevó a retrocesos permanentes de las capacidades estatales para formular e implementar políticas públicas. Y finalmente, la idea de establecer un nuevo orden social con un mínimo de protección social y amplia flexibilidad del mercado de trabajo se tradujo en niveles inéditos de desigualdad social.

Estos intentos de establecer un nuevo orden social en base al mercado y la desestatización de la economía del continente para colocarla bajo la guía de los organismos multilaterales y el decálogo del Consenso de Washington, comenzaron a generar un amplio consenso opositor y a comienzos del siglo XXI con el ascenso de Hugo Chávez al gobierno de Venezuela, se produjo un giro en la orientación política del continente.

El neoliberalismo puro enmarcado en el Consenso de Washington quedó enterrado (para siempre?) con las movilizaciones populares de los días 19 y 20 de diciembre de 2001 que obligaron a renunciar al ex presidente argentino Fernando de la Rúa, y a partir de allí se sucedió una rápida renovación de las administraciones que impulsaron las reformas neoliberales. El ciclo de gobiernos de una nueva izquierda se completó con los ascensos de Lula en Brasil y Kirchner en Argentina en 2003, Vázquez en Uruguay y Morales en Bolivia en 2005, Ortega en Nicaragua y Correa en Ecuador en 2006, a los que se agregaron Lagos y Bachelet en Chile en 2000 y 2006 respectivamente (MOREIRA, 2007, 2006).

De la mano de la recuperación económica que marcó un crecimiento sostenido del PBI superior al 3\% de promedio anual en los últimos cinco años (CEPAL, 2007a), esta época se caracterizó por la vigencia de un cierto optimismo colectivo y una mayoría del $54 \%$ de los latinoamericanos vuelve a considerar que la democracia es el mejor 
sistema de gobierno, recuperando la credibilidad de la democracia niveles anteriores a 2001 (CORPORACIÓN LATINOBARÓMETRO, 2007).

Aunque los perfiles y características de esta etapa pos Consenso de Washington aún buscan definirse y los desarrollos nacionales son en extremo variados, presenta prioridades comunes identificadas con la profundización de la democracia representativa, incorporando formas participativas de ejercicio de la soberanía popular, el interés de recuperar un papel más activo del Estado frente al funcionamiento del mercado, y la preocupación por limitar los efectos de la injusticia y la desigualdad social, (MOREIRA y otros, 2008; PNUD, 2004, 2002).

Ahora bien, aunque en el último lustro pareció central la dicotomía de una nueva izquierda gobernante dividida entre neo populistas y moderados, actualmente (sin que dicha dicotomía desaparezca) esas categorías se muestran insuficientes para abordar la compleja realidad política del continente. En realidad, aunque todavía conserva vigencia la idea que estamos con gran parte de la región gobernada por una nueva izquierda con una ala radical y otra moderada, comienza a perfilarse una realidad mas compleja a partir de la emergencia y consolidación de gobiernos que si bien se presentan como una reacción al neoliberalismo puro, a la vez representan una nueva derecha latinoamericana que necesariamente deben ser considerados en el análisis.

Para el caso, Claudio Katz define tres tipos de gobiernos contemporáneos en América Latina, a saber: conservadores, centro izquierda y nacionalismo radical. Los tres tendrían en común suceder a la ola neoliberal de los noventa, y se diferenciarían entre si por la política económica, la relación con Estados Unidos, la postura que ante ellos asume el establishment local y el balance y protección que brindan en sus gestiones de las conquistas democráticas y sociales (KATZ, 2007).

Por su parte, el sociólogo boliviano Fernando Calderón presentó recientemente una tipología que comprende cuatro categorías para clasificar a los gobiernos de la región: los que responden a una modernización conservadora a cargo de fuerzas de centro derecha, tal el 
caso colombiano y la mayoría de los países centroamericanos; los que se orientan por un reformismo pragmático conducido por fuerzas de centro izquierda, como en Chile, Brasil y Uruguay, aquellos casos que responden a un régimen de orientación nacional - popular, como el caso de Venezuela; y finalmente, el caso de gobiernos dentro de los parámetros del indigenismo neodesarrollista representada por los casos de Ecuador y Bolivia (VEGA, 2006; cf. CALDERÓN, 2007).

Primariamente, entonces, surge la necesidad de plantear esquemas de análisis que permitan abarcar la diversidad que va adquiriendo la política del continente en sus continuidades y rupturas respecto a la fase anterior, y sobre todo, recuperar (bajo nuevo formato) las distinciones entre izquierda y derecha tan clásicas en la historia de la región. Veamos este punto con cierto detenimiento.

Existe acuerdo que la derecha se identifica tradicionalmente en América Latina con la defensa de la economía de mercado, la propiedad privada y el autoritarismo habiendo tenido como aliados históricos a la Iglesia, las Fuerzas Armadas y los Estados Unidos. Y la izquierda, por su parte, se asocia históricamente a la defensa del desarrollo dirigido por el Estado, las expropiaciones y nacionalizaciones de empresas o tierras en nombre del bien común y su enemigo clásico fuera de fronteras ha sido siempre el imperialismo estadounidense (RODRÍGUEZ, 2004).

Por nuestra parte, consideramos que conservando estos rasgos tradicionales, es necesario tomar en cuenta elementos propios de la etapa pos Consenso de Washington en la que vivimos. Para ello, nos planteamos definir dos paradigmas de políticas públicas, a los que denominaremos Modelos Bogotá y Caracas, a partir de la consideración de una serie de elementos o dilemas que constituyen las variables para la comparación, a saber: la institucionalidad democrática, la justicia social, las relaciones entre Estado y mercado y la integración al mundo.

En suma, la consideración de estos elementos nos permitirá caracterizar y analizar la política y la sociedad latinoamericana en la fase pos Consenso de Washington, a la vez que ubicar los diferentes casos nacionales en una línea de continuidad.

En ese sentido, seguiremos aquí mas o menos heterodoxamente 
el camino weberiano de los tipos ideales, es decir, formularemos estructuras teóricas que nos permitan ordenar conceptualmente la realidad, y que nos permitirán indicar la distancia de los fenómenos históricos a tales adecuaciones de sentido (WEBER, 1984).

Estos dos modelos analíticos que consideramos útiles a fin de estudiar los acontecimientos políticos contemporáneos, se construyen acentuando las características de los casos históricos que le sirven de referencia (Colombia y Venezuela en la primera década del siglo XXI, respectivamente), pero de ninguna manera será posible reconocer completamente estos ejemplos concretos en la definición del modelo o tipo ideal.

Para cumplir con estos objetivos, el trabajo consta de tres partes y un epílogo. En la primera parte presentamos brevemente algunos de los rasgos principales del Modelo Bogotá, y en la segunda parte los elementos que definen su contracara, el Modelo Caracas. La tercera parte la dedicamos a algunas reflexiones sobre los casos desviados o intermedios, y en el epilogo expondremos algunas conclusiones surgidas de nuestro análisis.

\section{El Modelo Bogotá}

Sabido es que la democracia ha evolucionado desde una forma directa donde los ciudadanos gobernaban en asamblea, tal el caso de la Atenas del siglo V A.C., a una variante mas conservadora como el sistema representativo que hoy domina en el mundo occidental y que fue establecido paulatinamente con las revoluciones inglesa, estadounidense y francesa de los siglos XVII y XVIII.

Por ello conceptualmente la democracia deba ser entendida en dos sentidos, generalmente antagónicos. Por un lado, la democracia puede ser definida a partir de su cara representativa, esto es, según la conocida concepción shumpeteriana dado que no existe el gobierno del pueblo, lo que conocemos como democracia debe definirse como el gobierno de los políticos que compiten por el voto ciudadano. Por otro lado, dado que la representación nació en oposición al ejercicio directo, debería entenderse por democracia aquel régimen donde el pueblo 
gobierna directamente y sin intermediarios, siendo este el horizonte hacia el cuál deberían tender las incompletas democracias modernas.

Los dos modelos de política latinoamericana que estamos considerando dan una respuesta firme y concreta a esta disyuntiva entre democracia electoral y democracia participativa.

En primer lugar, desde el punto de vista político institucional, la esencia del Modelo Bogotá es la seguridad democrática. Por ello se procura el restablecimiento de la autoridad y la razón del Estado sobre enemigos internos como el terrorismo y la delincuencia, al tiempo que se busca mantener a toda costa el funcionamiento electoral. Esto marca una diferencia profunda con la derecha latinoamericana tradicionalmente golpista y antidemocrática. Este giro copérnico en las posiciones de la derecha latinoamericana se produce con el ascenso de Álvaro Uribe al gobierno de Colombia.

En mayo de 2002, Álvaro Uribe fue elegido por $53.2 \%$ de los votos, y luego de aprobarse una ley que habilitó la reelección presidencial, fue elegido por segunda vez en mayo de 2006 con el $62.2 \%$ de los votos. Su ascenso se vio favorecido por un sistema de partidos que en los noventa logró ampliar los participantes de la escena política, pero que vivía desde la crisis de 1999 en un cono de sombra e incertidumbre amenazado de ser alcanzado por el fenómeno de la ingobernabilidad (TANAKA, 2006).

En ese contexto, Uribe ganó las elecciones un poco sorpresivamente si nos guiamos por los sondeos de inicio de la campaña electoral, sin un partido nacional (que aún trata de construir), y prometiendo realizar una reforma política y constitucional que devolvieran la moralidad al sistema político colombiano. Debió enfrentar, además, la recesión económica de fines de los años noventa (la primera en los últimos cincuenta años en Colombia), así como recuperar para el Estado colombiano el monopolio de los medios de coerción cuestionado por la guerrilla, el narcotráfico y los paramilitares.

De sus promesas de campaña, pudo realizar en parte una reforma institucional que permitió consolidar el régimen electoral (aunque no la participación ciudadana), y fracasó (como veremos más 
adelante) en la atención de la cuestión social, limitándose a políticas de asistencia social focalizadas a los sectores en situaciones de emergencia sin impacto sustancial en la distribución del ingreso.

Pero donde su éxito fue manifiesto fue en el reforzamiento de la autoridad coercitiva estatal para asegurar la denominada seguridad democrática. En ese sentido, Uribe que recibiera un mandato pro orden muy fuerte de parte de sus votantes, tuvo como tareas fundamentales recuperar el monopolio de la coerción para el Estado y en ese marco se inscribe su política de desarme de los paramilitares y su presión sobre la guerrilla alejándola de las grandes ciudades, de las vías de comunicación hacia los centros turísticos del país y de los pequeños poblados (especialmente del sur del país) donde mantenía vínculos funcionales con los políticos locales. Este éxito en replegar a la guerrilla y desarmar a los paramilitares se acompañó de acciones de consolidación del poder estatal sobre el narcotráfico, como el asesinato en Venezuela a comienzos del 2008 de Wilber Varela, el último gran jefe narco colombiano (SANíN, 2004; VELÁSQUEZ, 2004).Sin embargo, dentro de este balance general es necesario realizar algunas precisiones.

Por un lado, su propuesta de paz con los paramilitares ha conseguido legalizar actores que han hecho de las prácticas criminales su modus operandi en la política (ÁLVARO, 2007). En ese sentido, ha suplantado unas fuerzas ilegales (los paramilitares) por otras (los que han abandonado las armas), aunque en conjunto las relaciones de la ilegalidad y la violencia política con el sistema político se mantiene intacto. En otras palabras, con nuevas caras, no ha hecho mas que consolidar los lazos entre el sistema político y la ilegalidad.

Por otro lado, la prioridad de la lucha contra enemigos armados ha tenido como consecuencia del fortalecimiento del Poder Ejecutivo y la subordinación del Congreso (una de las instituciones mas desprestigiadas de la escena política colombiana, a la que amenaza en reducir aún más cuantitativamente), un estilo paternalista de liderazgo, una coalición política concentrada en los sectores medios y altos de la sociedad colombiana, un proceso de movilización social de arriba hacia abajo bajo formas institucionalizadas de clientelismo, y una ideología de 
derecha que divide el campo de las fuerzas políticas en amigo-enemigo, donde el funcionamiento institucional deriva crecientemente hacia un régimen con rasgos autoritarios.

De esta manera, el Modelo Bogotá se constituye como una democracia electoral basado en el concepto de seguridad, donde la participación ciudadana es una mera consigna propagandística, y que mantiene en un lugar central de la escena a la fuerza militar y la violencia como instrumentos políticos a resolver los conflictos. Se trata de una nueva derecha que tiene tendencia a seleccionar elementos de conflicto que se solucionan con violencia organizada, antes que de consenso y búsqueda del dialogo para relacionarse con las otras fuerzas políticas. Mientras impulsa una política coercitiva agresiva contra los actores armados, paralelamente mantiene en partes importantes del país la ficción de un sistema electoral propio de las democracias mas avanzadas de la región.

Es por ello que Colombia califica con mucho esfuerzo dentro de la definición de poliarquía. Según esta, desde el punto de vista de los procedimientos una democracia es tal cuando están asegurados la libertad e igualdad de oportunidades para asociarse y expresar públicamente las preferencias políticas, así como se asegura un trato igualitario hacia los ciudadanos por parte de las autoridades. A pesar que existen fuerzas democráticas de derecha (como el uribismo y el partido conservador), y de oposición (desde socialdemócratas a neoliberales como el Partido Liberal liderado por el ex presidente Cesar Gaviria, a la vez que surgen fuerzas para competir con el gobierno electoralmente desde centro izquierdista como el Polo Democrático Alternativo que acaba de ganar la alcaldía de Bogotá en las elecciones de octubre de 2007), en numerosas regiones del país ser candidato a cargos electivos significa una condena a muerte. De hecho en las elecciones de octubre de 2007 numerosos candidatos que se opusieron a las alianzas locales de ex paramilitares y guerrilla fueron muertos por la acción de estos grupos. En otras palabras, la democracia colombiana es electoral pero tiene en su seno fuerzas armadas guerrilleras o en plan de desarme como los paramilitares que cuentan con un gran poder 
fáctico para cuestionar y vetar candidatos y partidos. Es más, en el caso de los grupos paramilitares reconocidos por el gobierno como actores políticos tienen estrechos lazos con el sistema político colombiano, y aún en una fase de desarme, esos lazos garantizan la supervivencia de mecanismos criminales de hacer política en la democracia colombiana ( ZGAIB, 2007).

A ello se suma el accionar represivo del Estado colombiano, que excede ampliamente a los contendientes armados. Las organizaciones de derechos humanos han denunciado que mas de once mil personas fueron asesinadas por los aparatos represivos del Estado desde que Uribe asumió la presidencia en 2002. Y finalmente debe tomar en cuenta además el elevado ausentismo electoral (en Colombia el voto no es obligatorio) que hacen que la participación sea inferior al cuarenta por ciento de los ciudadanos en condiciones de emitir el sufragio.

Considerando todos estos elementos resulta que en diversas clasificaciones de amplia aceptación en la ciencia política contemporánea, el caso de Colombia es categorizado como una democracia electoral en los niveles medios o bajos de los índices que miden el funcionamiento procedimental y la calidad de la democracia en América Latina (ALCÁNTARA, 2007), ya sea como un caso de democracia semi libre (FREEDOM HOUSE, 2007) o de desarrollo democrático intermedio (ADENAUER, 2007).

En segundo lugar, debemos considerar la respuesta que cada modelo da a la cuestión de la justicia social, esto es, cuáles son las herramientas que cada tipo ideal prescribe para enfrentar el problema de la desigualdad social y como se enuncian las metas de la igualdad social y como alcanzarlas.

Definida a grandes rasgos, la cuestión social hace referencia a las diferentes categorías de desigualdad que hacen de América Latina el continente más desigual del mundo según criterios de ingreso. La misma presenta dos rutas de salida, no necesariamente contradictorias ni secuenciales entre si, a saber: la asistencia social directa y las reformas estructurales.

Por la primera se establece algún tipo de solución de corto plazo 
que permita sortear la situación de emergencia, por ejemplo a través de una asignación monetaria mensual a aquellas personas que están viviendo por debajo de la línea de pobreza. Por la segunda, se trata de implementar medidas que en el mediano y largo plazo permitan establecer un horizonte de solución permanente a la misma, como por ejemplo medidas fiscales para la redistribución del ingreso, una reforma del régimen de tenencia de la propiedad de la tierra (reforma agraria) y asegurar logros educativos de calidad a los estratos sociales más desfavorecidos.

El Modelo Bogotá se define claramente por la vía de las soluciones asistencialistas y focalizadas de corto plazo. En realidad esto es el piso mínimo de funcionamiento de cualquier democracia en la región, y difícilmente algún gobierno latinoamericano pueda apartarse en el mediano plazo de implementar políticas de asistencia directa a los sectores de la población que se encuentran por debajo de la línea de pobreza. En términos ideales lo característico del Modelo Bogotá es que esta es la única vía que se establece como ruta de salida.

$Y$ en ese sentido, no hay ningún giro copérnico de la nueva derecha respecto a sus raíces, como lo vimos en el plano institucional. $Y$ a pesar que la derecha en América Latina tradicionalmente defendió políticas sociales focalizadas, y ellas fueron inútiles a la hora de contener las grandes explosiones sociales de los últimos años, los nuevos exponentes de esta orientación ideológica continúan implementando medidas de carácter parcial y apostando por esta vía a mantener controlado el conflicto social a la vez que reproducir los esquemas de desigualdad social vigentes.

En el caso colombiano, al asumir Uribe el $51.1 \%$ de los colombianos estaban bajo la línea de pobreza, y a pesar de años de sostenido crecimiento económico, en el 2005 la pobreza había descendido algo más de 3 puntos ( $46.8 \%$ de la población), en un contexto donde la pobreza disminuyó más de 7 puntos en América Latina desde $44 \%$ a $36.5 \%$ de la población entre 2002 y 2006 . El gasto público social continúa descendiendo, ubicándose en el 2006 en 13.4\% del PBI y era el cuarto país latinoamericano con el mayor coeficiente de 
desigualdad (Gini 0.584) luego de Bolivia, Brasil y Honduras. La migración desde las zonas rurales hacia las ciudades se mantenía como un fenómeno constante, debido a la combinación de pobreza y guerra, y en la primera década del siglo XXI la población urbana colombiana creció a un ritmo anual del $2.43 \%$, frente al $0.51 \%$ de crecimiento de la población rural en el mismo período (CEPAL, 2007b).

En síntesis, las políticas sociales de la administración de Uribe se mantienen dentro de los parámetros neoliberales de los años noventa, y los planes sociales focalizados hacia los sectores más vulnerables no han afectado la desigual distribución del ingreso ni la pobreza en su conjunto. Se trata de asistir socialmente mientras se forma una coalición social entre los más ricos y los más pobres (tan recurrente en los noventa), que perpetúa a aquellos en el poder y deje a estos siempre en el fondo de la escala social. En tercer lugar, debemos considerar como cada Modelo establece cursos de acción respecto a la problemática relación entre el Estado y el mercado.

Una política pública es un curso de acción o proceso sobre objetivos públicos definido e implementado de manera democrática por el Estado. Muchas veces ello se da con participación de la comunidad, incluyendo al sector privado.

Desde mediados de los años setenta, la región latinoamericana asiste a una nueva época del capitalismo mundial incorporándose a los procesos globalizadores que significan un retroceso del Estado desarrollista en la formulación e implementación de políticas públicas y un avance de los organismos internacionales y los sectores privados a través de los llamados mecanismos de mercado. Luego de dos décadas de reformas neoliberales, el retroceso de la capacidad institucional del Estado y el aumento significativo de los problemas sociales introdujo en la etapa pos Consenso de Washington el problema de la conducción de los procesos sociales, y la necesidad de recuperar el papel del Estado frente al mercado.

Frente a este dilema, el Modelo Bogotá se caracteriza por mantener al mínimo posible la participación del Estado en los procesos económicos, dejando la conducción de las políticas en manos del sector 
empresarial privado y los organismos multilaterales de crédito.

Durante las dos gestiones de Uribe las políticas hacia el sector público se caracterizaron por perseguir los objetivos de disciplina fiscal, disminución del gasto y una reforma del Estado tendiente a asegurar una mayor presencia de los mecanismos de mercado en la definición de los lineamientos macroeconómicos (HERNÁNDEZ, 2007).

De esta manera, en nuestro caso de referencia el gobierno de Uribe ha mantenido la tendencia de predominio del mercado sobre el Estado en la definición de las políticas públicas, y en cierta manera ha acompañado el patrón histórico de la sociedad colombiana, que marca un rechazo al papel del Estado en los procesos económicos. Según los datos que entrega el Latinobarómetro (2007) tres de cada cuatro colombianos consideran que el mercado es el mejor asignador de recursos, lo que la convierte en la sociedad de tendencia ideológica mas pro mercado del continente.

Ésta referencia a la órbita económica, no se contradice por supuesto con el hecho que el Estado tiene un papel central en la vida política colombiana, y que se perpetúa el patrón clientelista que caracteriza a la misma, donde los recursos continúan fluyendo desde el Estado central a las regiones y los municipios dominando el espacio público con asignaciones de partidas presupuestales con patrones clientelísticos y corruptos, ante la pasividad de la ciudadanía y la sociedad civil (SUDARSKY, 2007). El Estado colombiano, más que otros está ocupado en defender los intereses privados y son ellos los que se realizan a través de estos mecanismos.

Finalmente y en cuarto lugar, debemos considerar la manera en que cada Modelo aborda el plano de la integración regional. Se trata aquí quizás de uno de los elementos donde encontramos la mayor divergencia manifiesta entre los Modelos Bogotá y Caracas en consideración. Se trata sin duda de una diferencia política significativa, y que hace a la tradicional división entre derecha e izquierda del continente como ninguna de las anteriores, dado que las identificaciones ideológicas históricas del continente han marcado que la derecha se acerca a Estados Unidos y la izquierda en la misma medida y proporción 
se aleja de ese país.

El Modelo Bogotá se define claramente por una estrecha relación con Estados Unidos, dejando que su política interior y exterior se estructure en virtud de los intereses estadounidenses acompañando los objetivos y evolución de aquella.

En este plano interno, el gobierno de Uribe es continuador directo del importante papel que desde los años sesenta juegan en Colombia los organismos internacionales en la determinación y evaluación de la política económica. Desde esa década, tanto el Fondo Monetario Internacional como el Banco Mundial y el Banco Interamericano de Desarrollo tienen una importante articulación con las principales instituciones de política económica colombiana, lo cual marca un sesgo particular en el continente (BRAUN y otros, 2007).

En el plano de la política exterior el gobierno de Uribe está atado al denominado Plan Colombia, que en $\mathbf{2 0 0 0}$ firmaran su antecesor en el cargo Andrés Prastrana y Bill Clinton y que significó adherir a un plan de inversiones y desarrollo con participación del gobierno colombiano y la comunidad internacional, especialmente Estados Unidos. En ese sentido, la defensa de intereses conjuntos se traduce un alineamiento de las políticas entre Bogotá y Washington. La misma se expresa tanto en el plano militar que a comienzos del 2008 alcanzó los 4000 millones de dólares a los efectos de combatir el narcotráfico y la guerrilla, como en el plano comercial, con la inminente firma del Tratado de Libre Comercio (TLC) entre ambos países.

\section{EI Modelo Caracas}

Como vimos en el apartado anterior, en términos teóricos la democracia tiene una conceptualización bifronte, mezcla de representatividad y participación. En ese sentido, para definir las características de cada Modelo que estamos considerando, atendemos al énfasis que en ellos se dan tanto a los aspectos formales electorales como aquellos más sustantivos de la extensión de los procedimientos participativos y mecanismos de democracia directa.

En primer lugar, desde el punto de vista político institucional, la 
esencia del Modelo Caracas es la profundización de la democracia participativa. Dentro del mismo, la democracia tiene un fuerte componente deliberativo, participativo y directo, existiendo un proceso de toma de decisiones con participación ciudadana que se considera esencial a una definición de las políticas públicas democráticas.

Hugo Chávez asumió como presidente de Venezuela en 1999, y ese año reformó la Constitución para allanar el camino a la revolución bolivariana. Luego de sortear un golpe de Estado en 2002 y triunfar en un referéndum revocatorio en 2004, fue reelegido presidente en 2006 siendo derrotado en 2007 en un nuevo referéndum, donde pretendía reformar nuevamente la Constitución e introducir, entre otras variantes, la reelección indefinida.

En este proceso, se transformó en el presidente del gobierno que mejor representa a la nueva izquierda del espectro político de América Latina. La caracterización de su programa ha sido hecha como socialismo del siglo XXI, que en pocas palabras, comprende en el plano político la combinación de las instituciones de la democracia representativa con instancias de participación popular como el referéndum y diversos mecanismos de consulta y control social de las decisiones de los gobernantes, un régimen mixto de propiedad donde conviven la propiedad privada con la estatal y la cooperativa o comunitaria, un sistema de producción donde la propiedad individual coexiste con sistemas cogestivos entre empresarios y trabajadores, y la extensión y profundización del Estado de Bienestar, asegurando por ejemplo que los sistemas de educación y salud sean efectivamente universales (REYES, 2006).

Una característica política del Modelo Caracas es el cuestionamiento al sistema de partidos políticos tradicional, y en ese sentido, Hugo Chávez ha sido un crítico constante del neoliberalismo y de los partidos tradicionales venezolanos Acción Democrática (AD) y Comité de Organización Política Electoral Independiente (COPEI) que fueron soporte del mismo, y ha sabido combinar el carácter procedimental de la democracia con la política en las calles, impulsando la denominada democracia participativa y protagónica guiado por la idea 
que los ciudadanos no solo deben votar sino también formular, implementar y controlar las políticas públicas.

En esta concepción, el papel del Estado seria facilitar el proceso de toma de decisiones de los ciudadanos organizados, lo cual lleva a que el sistema político venezolano viva un momento de intensa movilización social de los sectores populares tratando de influir en la determinación de las políticas públicas (MAYA, 2006).

Sin embargo, la profundización de la democracia y el impulso hacia formas participativas directas, ha tenido como contracara un aumento de las formas personalistas de liderazgo, la emergencia del fenómeno del culto a la personalidad, las iniciativas que pretendían eternizar el líder en la presidencia de Venezuela, la polarización política extrema con ciertas medidas que significan la imposibilidad plena de expresión para la oposición, y el control que tiene el Estado sobre las organización populares, todo lo cual ha llevado a que Venezuela figure entre las democracias semi libres (FREEDOM HOUSE, 2007) y de menor desarrollo democrático (ADENAUER, 2007).

Es mas, para algunos Venezuela va caminando a convertirse en el ejemplo más acabado de las nuevas formas que adopta el populismo en el continente, en base al liderazgo carismático que une a Chávez con sus bases de apoyo, la inclusión movimientista a la política de sectores populares hasta ese momento excluidos de la escena y a la vez el carácter paternalista de la relación del Estado con esos sectores populares (FREIDENBERG, 2007).

Respecto al elemento social, el Modelo Caracas se caracteriza por incluir junto a la preocupación por dar solución a la desigualdad socioeconómica, también otras formas de desigualdad como las de género, étnicas y regionales. En ese sentido, la vía de salida de estas situaciones hacia escenarios de justicia social suelen ser las llamadas reformas estructurales tales como las del sistema de salud, de educación, de la propiedad de la tierra y los recursos naturales, etc. En el Modelo Caracas son casi nulas las posibilidades de alianzas entre sectores ricos y pobres, y presenta muy altos los niveles de conflictividad social.

En ese sentido, en el caso del gobierno de Hugo Chávez en 
Venezuela la aplicación de políticas sociales en gran escala y altos grados de universalidad permitieron un extraordinaria disminución de los porcentajes de población por debajo de la línea de pobreza de $48.6 \%$ a $30.2 \%$ (es decir, 18 puntos) entre 2002 y 2006, manteniendo constante el gasto público social en $11.7 \%$ del PBI (a pesar de la tendencia regional a su disminución), siendo además el país más igualitario del continente con un Coeficiente Gini de 0.441 (CEPAL, 2007b).

Pero además se destacan el papel jugado por la legislación promulgada a los efectos de democratizar el acceso a la propiedad de la tierra (rural o urbana), que fuera una fuente importante de conflictos con el sector empresarial, y que se reflejara en el intento de golpe de Estado de 2002 liderado por los sectores empresariales venezolanos. Según cálculos conservadores, uno de cada cuatro venezolanos está participando activamente en los Comités de Tierra creados a los efectos de llevar adelante la lucha popular por la tenencia de la tierra, y los sectores populares mantienen una autonomía impensada respecto a las instancias gubernamentales encargadas de aplicar la legislación.

Estos programas que pretenden reducir la desigualdad social a partir de un avance importante hacia la igualdad y la democratización social, se complementan con programas donde se intenta respaldar el acceso masivo de los sectores populares al sistema educativo y la salud. De todos modos, la derrota electoral en el referéndum de diciembre de 2007 para reformar la Constitución, además de una crítica al excesivo personalismo del Presidente Chávez significó también un llamado de atención a la ineficiencia con que son implementados muchos de estos programas, básicamente a partir de los obstáculos que surgen desde la burocracia estatal (WILPERT, 2008).

En tercer lugar, veamos el papel que se le asigna al Estado en el desarrollo en el Modelo Caracas. La izquierda latinoamericana contemporánea ha cambiado. Hoy existe una nueva izquierda que ha producido cambios ideológicos importantes, corriéndose hacia el centro, y entonces ser de izquierda actualmente en América Latina es aceptar el mercado, y consecuentemente, la propiedad privada de los medios de 
producción.

Sin embargo, el Modelo Caracas participa de una concepción donde el papel del Estado es orientar, articular y actuar sobre el mercado, hasta convertirse el mismo un planificador y empresario. Así en Venezuela, en el plano económico el chavismo se propone avanzar en la estatización y nacionalización de los recursos naturales. Se trata de una concepción neo desarrollista, que deja con niveles importantes de acción y autonomía a las organizaciones de la sociedad civil, desde el momento en que el gobierno impulsa cooperativas $y$ formas autogestivas de pequeñas y medianas empresas, sea en el sector productivo o de servicios. Este respaldo al desarrollo de la economía social se apoya en un sistema de micro créditos y programas de capacitación y apoyo a la comercialización.

Finalmente, en el plano de la integración regional, el Modelo Caracas apuesta fuertemente por la integración de América Latina, oponiéndose a las políticas de Estados Unidos en la región, impulsando iniciativas de integración latinoamericana en el plano energético, financiero y militar.

En nuestro caso de referencia, Hugo Chávez ha mostrado un fuerte discurso anti estadounidense, e impulsado iniciativas económicas y hasta militares que molestan profundamente a Estados Unidos. Por ejemplo, la iniciativa de realizar una alianza armada entre países de América Latina (ALTMANN, 2008), o la de crear el Banco del Sur, una propuesta que recibió al aceptación de los países del Cono Sur, Bolivia y Ecuador, la negativa de Colombia, con la cuál se aspira a crear un banco de desarrollo regional que sirva de alternativa a los organismos financieros multilaterales como el Fondo Monetario Internacional (FMI), el Banco Mundial (BM) y el Banco Interamericano de Desarrollo (BID).

\section{Las desviaciones o casos intermedios}

No existe en realidad ningún caso nacional que signifique una representación perfecta de alguno de los modelos que hemos presentado. En ese sentido, la inspiración para la construcción conceptual presentada de los Modelos Bogotá y Caracas ha estado en 
los gobiernos de Uribe y Chávez, respectivamente, pero no deben exagerarse las correspondencias entre lo ideal y lo real. E incluso podría ser perfectamente posible estudiar las desviaciones colombiana y venezolana a los respectivos Modelos, algunas de las cuáles aparecen señaladas en este texto.

Ahora bien, si lo anterior es cierto, además hay que decir que América Latina no es un continente partido en dos, y si bien en términos teóricos afirmamos que se trata de un esquema de modelos bipolares, la realidad muestra múltiples casos intermedios. Esto es, la mayoría de regímenes políticos del continente actúan en realidad de manera más moderada que los tipos ideales que tienen como espejo.

Por un lado, los casos más cercanos a la seguridad democrática del Modelo Bogotá están (obviamente) en el caso del gobierno de Uribe, a lo que se agrega el Cono Sur, América Central y (fundamentalmente) México. En ese sentido, el gobierno panista se presenta como un ejemplo de democracia electoral al mínimo, asistencia social focalizada, una fuerte orientación hacia políticas centradas en el mercado, combinado con una extranjerización de la economía y un fuerte acercamiento a Estados Unidos.

También es interesante considerar como paradigmático el caso argentino, a quienes muchos ubicarían en el espectro de gobiernos y países mas cercanos al Modelo Caracas. Los gobiernos de Kirchner y su esposa no han intentado democratizar a algunos actores centrales como el sindicalismo peronista, ni han realizado una reforma tributaria que permita una distribución progresiva del ingreso, ni han puesto en manos de la comunidad tierras publicas improductivas, y mucho menos se han propuesto nacionalizar los recursos naturales en manos de extranjeros promoviendo un debate nacional sobre la extranjerización de la propiedad de la tierra. Todas sus iniciativas se limitan a intentar moralizar aspectos corruptos del sistema político y asegurar las condiciones macroeconómicas para el desarrollo de un capitalismo nacional, lo cuál lo ubica bastante lejos del Modelo Caracas.

Si esto es válido para el progresismo peronista de los Kirchner, con más razón se aplica al resto de los países del Cono Sur que 
obedecen a pie juntillas las políticas emanadas de los organismos financieros internacionales, lo que hace que en su conjunto el sur del continente, otrora la avanzada radicalizada del mismo, hoy se aproxime decididamente al Modelo Bogotá de la política latinoamericana, esto es, aquel que procure el mantenimiento del status quo mas que su transformación.

Por el lado izquierdo del mapa político de la región y cercano al socialismo del siglo XXI que proclama Chávez y que sirve de referente al Modelo Caracas, sólo se ubican dos países andinos, Ecuador y Bolivia. En Ecuador, el gobierno de Rafael Correa instaurado desde 2006 impulsa una serie de iniciativas de reforma constitucional y tributaria, control de las industrias y fuentes de recursos naturales e integración latinoamericana que tienen en la vereda de enfrente a los sectores económicamente dominantes de Ecuador (que amenazan con un paro patronal) y en alerta a Estados Unidos.

En Bolivia, luego de dos años de una durísima batalla política, el gobierno de Evo Morales logró que en diciembre de 2007 se aprobara la nueva Constitución, cuatrocientos artículos que proclaman el reconocimiento plurinacional del Estado boliviano y que reafirman un rol activamente neo desarrollista para el Estado. La misma fue desconocida por el oriente y el sur del país, y significo que Bolivia ha quedado prácticamente en dos. El gobierno de Evo Morales actúa en nombre de las tradiciones del indianismo boliviano unificado en sus alas moderada y radical, actuando coordinadamente en la Asamblea Constituyente a través de los representantes de los sindicatos y comunidades agrarias indígenas incluidos en el partido de gobierno del Movimiento $\mathrm{Al}$ Socialismo (MAS) (LINARES, 2007). Los partidarios del gobierno de Evo lograron incluir en la nueva Constitución que será sometida a referéndum la reelección presidencial, varias formas de propiedad comunicaría la nacionalización de los recursos naturales y la prohibición de privatizar los servicios públicos. Queda incluso para decisión de la ciudadanía poner un limite máximo a los latifundios en el país, lo cual abre las puertas a una redistribución de la tierra en el país. La oposición, aglutinada en torno al gobierno de Santa Cruz y con el apoyo de Estados 
Unidos, reivindica para si las autonomías regionales. Al igual que las radicalizadas derechas colombiana y venezolana se expresa en las calles, con manifestaciones de masas y llamados a la rebelión cívica que en ocasiones ha significado el enfrentamiento directo con las organizaciones de izquierda que apoyan al gobierno. El gobierno ha decidido que la Bolivia mayoritaria se alinee en el eje izquierda del continente, pero hoy el país parece estar en frente a una crisis de proporciones producto del callejón sin salida que enfrentan las fuerzas políticas del gobierno y la oposición.

\section{Conclusiones}

Álvaro Uribe y Hugo Chávez alcanzaron el gobierno con características similares: outsiders del sistema político, se presentaron como salvadores de la patria, en un contexto de desencanto con la democracia, crisis de los partidos políticos tradicionales y sociedades caracterizadas por cierta impronta anti política. Ambos fueron rápidamente etiquetados como fenómenos neopopulistas, y las mayorías electorales se movilizaron tras ellos convencidos por las promesas de reformas institucionales y soluciones a las crisis económica y social luego de dos décadas de neoliberalismo.

Las similitudes continuaron una vez en el poder y ambos se caracterizaron por un ritmo vertiginoso de gobernar, un estilo personalista de liderazgo que lejos de agotarse ha logrado renovar un amplio apoyo popular, lo que les ha permitido a ambos la reelección.

En todo caso, todo este conjunto de características comunes, sumado a la fuerte intención de tener presencia e incidencia en el escenario regional, han llevado a una traslación del eje de la nueva política latinoamericana, en sus continuidades y rupturas, desde el Cono Sur a la parte norte del continente.

El escenario político hoy América Latina presenta una nueva derecha y una nueva izquierda que se enfrentan a las políticas neoliberales de los noventa, recuperando algo de las mismas y tratando de corregir el rumbo, aceptando la democracia representativa, intentando mitigar los efectos de la pobreza y la desigualdad social, 
buscando fortalecer los Estados y desde el punto de vista regional, convertirse en lideres de los demás países de la región. Pero mas allá de este campo en común, son profundamente contradictorias, y una serie de elementos permiten fijar la atención en ello. En este trabajo hemos intentado plantear una distinción conceptual, los que denominamos Modelos Bogotá y Caracas, a fin de comprender la política latinoamericana en su complejidad y globalidad.

El Modelo Bogotá acentúa las características definitorias de una derecha radical, en tiempos del pos Consenso de Washington, una nueva derecha que quiere diseñar e implementar políticas promercado con asistencia social focalizada en gran escala, y que en plano internacional se ubica en la escena con Bush, Aznar, Berlusconi y Sarkozy. Se trata de una derecha democrática pero que su vocación de poder le impide acercarse al centro político cada vez que su ascenso o manutención del poder esta en riesgo. En otras palabras, no tiene escrúpulos en usar medios violentos para luchar, llevando la legalidad democrática al extremo de la cuasi ruptura.

El Modelo Caracas, por su parte, hace referencia a una nueva izquierda radical que tiene como objetivos profundizar la democracia y redistribuir el ingreso, implementar reformas estructurales en la tenencia de la tierra, universalizar el acceso a los sistemas educativo y de salud que permitan grados inéditos de igualdad social en el continente más desigual del mundo, fortalecer el Estado y promover la integración latinoamericana de manera que los países de la región tengan autonomía en sus decisiones de políticas públicas respecto a Estados Unidos y los organismos multilaterales de crédito.

En este contexto general, los Modelos Bogotá y Caracas permiten una clasificación de los diferentes casos nacionales. Como un péndulo, la región oscila entre inclinarse hacia la nueva derecha que propone el Modelo Bogotá o la nueva izquierda que propone el Modelo Caracas, lo cual plantea los mayores dilemas a los actores que se encuentran en las posiciones intermedias, especialmente a los que se ubican desde posiciones moderadas en el lado izquierdo del espectro. Hoy parece que la mayoría de ellos han tomado la decisión de alejarse del Modelo 
Caracas, intentando mantenerse en el punto de equilibrio de la balanza. ¿Hay chances de francés Onfray: la izquierda está "muerta por su renuncia a las ideas a fin de venderse ventajosamente al mejor dispuesto a permitirles disfrutar una vez más de los palacios presidenciales o de las prebendas del poder en la república" (ONFRAY, 2007:123).

Los próximos años de la política latinoamericana parecen presentarse con elecciones sin fraudes, pero sin incorporar elementos participativos sustantivos; políticas sociales con grados diversos de universalidad pero sin disminuir sustancialmente los grados de injusticia social, intenciones neo desarrollistas coexistiendo con orientaciones pro mercado muy extendidas, y afanes de integración latinoamericana en paralelo a la influencia constante de Estados Unidos en las políticas de la región.mantener de manera permanente esta posición y proclamarse de izquierda? Quizás sea oportuno citar las palabras del filósofo.

Carlos Moreira é doctor en Ciencia Política (FLACSO México) e director de FLACSO Uruguay.

E-mail: cmoreira@flacso.edu.uy

\section{Referencias:}

ADENAUER, K. Indice de Desarrollo Democrático de América Latina, 2007. Disponível em: <http://www.idd-lat.org >. Acesso em: 04 feb. 2008.

ALCÁNTARA, M. Luces y sobras de la calidad de la democracia en América Latina, 2007. Disponível em:<http://www.iberoame.usal.es>. Acesso em: 04 feb. 2008.

ALTMANN, J. Alba. ¿un proyecto alternativo para América Latina?. Disponível em: $<$ www. realinstitutoelcano.org $>$. Acesso em: 08 feb. 08.

ÁLVARO, M. La parapolítica. La infiltración paramilitar en la clase política colombiana. In VI CONGRESO DE LATINOAMERICANISTAS EUROPEOS, 2007. Bruselas. Banco de Papers. Bruselas: CEISAL, 2007.

BRAUN, M. et all. Caso de estudio colombiano: FEDESARROLLO. Disponible em: <http://www.cippec.org>. Acesso em: 06 feb. 2008.

CALDERÓN, F. Tiempos de agitación. Tiempos de cambio. Sociedad y 
democracia en los países andinos meridionales. In: SORJ, B.; OLIVEIRA, M. de (Org.). Sociedad civil y democracia en América Latina: crisis y reinvención de la política. Rio de Janeiro: São Paulo: Centro Edelstein, IFHC, 2007. p. 155-206.

CEPAL. Informe Económico y Social 2006-2007, 2007a. Disponível em: <http://www.cepal.org >. Acesso em: 05 feb. 2008.

Panorama social de América Latina, 2007b. Disponível em: <http://www.cepal.org >. Acesso em: 05 feb. 2008.

CORPORACIÓN LATINOBARÓMETRO. Informe Latinobarómetro 2007. Disponível em: <http://www.latinobarómetro.org>. Acesso em: 04 feb. 2008.

FREEDOM HOUSE. Freedom in The World, 2007. Disponível em: <http://www.freedomhouse.org>. Acesso em: 04 feb. 2008.

FREIDENBERG, F. La tentación populista: una vía al poder en América Latina. Madrid: Editorial Síntesis, 2007.

HERNÁNDEZ, C. G. Neopopulismo en Colombia: el caso del gobierno de Álvaro Uribe Vélez. Iconos- Revista de Ciencias Sociales, Quito, n. 27, p. 147-162, jan. 2007.

LINARES, A. G. El desencuentro de dos razones revolucionarias: indianismo y marxismo. Cuadernos de Pensamiento Crítico Latinoamericano, CLACSO, Buenos Aires, n. 3, p 1-4, dez. 2007.

SANÍN, F., G. Ilegalidad y sistema político en Colombia: la agenda de Uribe Vélez. Nueva Sociedad, Caracas, n. 192, p. 59-71, jul.-ago. 2004.

ZGAIB, M. A. El terror parapresidencial: a caballo entre la parapolítica y la insurgencia. Semanario Virtual Caja de Herramientas, Bogotá, n. 97, feb. 2008. Disponível em: <http://www.viva.org.co>. Acesso em: 21 jun. 2008.

KATZ, C. Gobiernos y regímenes en América Latina. In: HENRÍQUEZ, J. (Org.). Los '90: fin de ciclo. El retorno a la contradicción. Buenos Aires: Editorial Final Abierto, 2007. p 43-66.

MAYA, M. L. Del viernes negro al referendo revocatorio. Caracas: Alfadil Ediciones, 2006.

MOREIRA, C. El nuevo mapa político en América Latina, ¿giro a la izquierda? Anuario Ciencias Políticas, Santiago de Chile, n. 6, p. 53-73. 2006.

Los dilemas de la nueva izquierda gobernante en América Latina. Revista Pensamento Plural, Pelotas, ano I, n. 1, p. 49-63, dez. 2007. 
MOREIRA, C.; R., D.; GÓMEZ LEYTON, J.C. (Orgs.). La nueva política en América Latina: Continuidades y rupturas. Montevideo: FLACSO/ UNLa/ UArcis, 2008.

ONFRAY, M. La pertenencia de existir. Manifiesto hedonista. Buenos Aires: Ediciones de la Flor, 2007.

PNUD. Informe sobre desarrollo humano. Madrid: Mundi-Prensa, 2002. - La democracia en América Latina. Hacia una democracia de ciudadanas y ciudadanos. Buenos Aires: Aguilar, Altea, Taurus, Alfaguara, 2004.

REYES, O. Sobre el socialismo del siglo XXI en Venezuela. Stockholm Review of Latin American Studies, Stockolmo, n. 1, p. 84-104, nov. 2006.

RODRÍGUEZ, O.A. Derechas y ultraderecha en el mundo. México: Siglo XXI, 2004.

SUDARSKY, J. Del clientelismo a la Nueva Cultura Política en Colombia. Perspectiva desde la medición del Capital Social. In: CLARK, T. N.; NAVARRO, C. J. (Orgs.). La Nueva Cultura Política. Tendencias globales y casos iberoamericanos. Buenos Aires: Miño y Dávila, 2007. p. 165192.

TANAKA, M. Los sistemas de partidos en los países andinos, 1980-2005. Reformismos institucional, autoritarismos competitivos y los desafíos actuales. Notre Dame: Helen Kellog Institute for International Studies, 2006. (Working Paper n. 324).

VEGA, J.E. Reflexiones y preguntas sobre las percepciones políticas de las élites brasileña, mexicana y argentina. Buenos Aires: PNUD, 2006.

VELÁSQUEZ, A. V. El gobierno de Alvaro Uribe: proyectos y resultados. Nueva Sociedad, Caracas, n. 192, p. 85-97, jul.-ago. 2004.

WEBER, Max. Economía y sociedad. Esbozo de sociología comprensiva. México: Fondo de Cultura Económica, 1984.

WILPERT, G. Primera derrota electoral para Hugo Chávez. Alerta para la revolución bolivariana. Le Monde Diplomatique, Santiago de Chile, año 9, n.103, p. 6-8, jan. 2008. 